\title{
Long-term outcome of medullary thyroid carcinoma in patients with normal postoperative medical imaging
}

\author{
G Pellegriti',4, S Leboulleux ${ }^{1,4}$, E Baudin', N Bellon², C Scollo', JP Travagli ${ }^{3}$ and M Schlumberger*, \\ 'Service de Médecine Nucléaire et de Cancérologie Endocrieme, Institut Gustave Roussy, Villejuif, France; 'Département de Biostatistique et de Santé \\ Publique, Institut Gustave Roussy, Villejuif, France; ${ }^{3}$ Senvice de Chirurgie Générale, Institut Gustave Roussy, Villejuif, France
}

\begin{abstract}
Imaging-detected relapses are observed in a significant proportion of patients with medullary thyroid carcinoma (MTC) with normal postoperative imaging studies. The aim of this study was to search for prognostic factors of imaging-detected relapse. This retrospective study was performed in 63 consecutive MTC patients with normal postoperative medical imaging. After surgery, the basal calcitonin (CT) level was undetectable in 35 patients and elevated in 28. During follow-up, 18 patients developed a clinical or imaging-detected relapse (29\%) in the neck and/or at distant sites: 15 had an elevated postoperative basal CT level and three had an undetectable postoperative basal CT level. At multivariate analysis, the significant parameters predictive of imaging-detected relapse were the postoperative plasma CT level and the tumour extension (PT). The 3- and 5-year relapse-free survival rates were 94 and $90 \%$ in patients with an undetectable postoperative basal CT level, and 78 and $61 \%$ in patients with a detectable basal CT level $(P<0.05)$. The 3 - and 5 -year relapse-free survival rates were 92 and $85 \%$ in the $\mathrm{PTI}-3$ patients, and 57 and $46 \%$ in the pT4 patients $(P<0.0 \mathrm{I})$. These results show that postoperative $\mathrm{CT}$ level and tumour extension are critical prognostic factors for the identification of patients at a high risk of relapse.

British Journal of Cancer (2003) 88, I537- 1542. doi:I0.1038/sj.bjc.6600930 www.bjcancer.com

(c) 2003 Cancer Research UK
\end{abstract}

Keywords: medullary thyroid cancer; calcitonin; prognostic factors; relapse-free survival

Even following apparently complete surgical resection of medullary thyroid carcinoma (MTC), the postoperative plasma calcitonin (CT) level remains elevated in a large proportion of patients. Elevated plasma CT indicates the persistence of neoplastic foci. Furthermore, rare relapses have been reported in patients with an undetectable basal CT after initial surgery (Modigliani $e t$ al, 1998).

In patients with elevated CT levels, the sensitivity of imaging methods (including ultrasonography, computed tomography scan, MRI or scintigraphy) for the detection of residual disease is limited for lesions other than gross residual disease (Frank-Raue et al, 1992). Selective venous sampling catheterisation with plasma CT measurements appears to be the most sensitive and specific method for localising persistent disease. However, even after further surgery based on the results of venous sampling, $62-98 \%$ of the patients still have elevated CT levels (Frank-Raue et al, 1992; Abdelmoumene et al, 1994; Moley et al, 1998; Kebebew et al, 2000b).

Five and 10-year overall survival rates in MTC patients without initial distant metastases range between $60-100 \%$ and $55-100 \%$, respectively, suggesting that an aggressive therapeutic approach may not be appropriate in all patients (Rougier et al, 1983; Saad et al, 1984; Schroder et al, 1988; Raue et al, 1993; Dottorini et al,

\footnotetext{
* Correspondence: Dr M Schlumberger, Service de Médecine Nucléaire, Institut Gustave-Roussy, 39 rue Camille Desmoulins, 94805 Villejuif Cedex, France; E-mail: schlumbg@igr.fr

${ }^{4}$ Contributed equally to this study.

Received 7 November 2002; accepted 25 February 2003
}

1996; Scopsi et al, 1996; Bergholm et al, 1997; Modigliani et al, 1998). In patients with elevated plasma CT level and with no evidence of gross residual disease after initial surgery, the rate of clinical or imaging-detected relapses is about $40 \%$ during the subsequent follow-up (Rougier et al, 1983; Van Heerden et al, 1990). However, prognostic factors for relapse have not been clearly identified in these patients. The aims of our single centre retrospective study were (1) to describe the long-term outcome of MTC patients without clinically and imaging-detectable disease after initial neck surgery and (2) to search for prognostic factors for imaging-detected relapse.

\section{METHODS}

\section{Patients}

Imaging investigations (including a neck ultrasonography, a chest computed tomography scan, an abdominal ultrasonography or an abdominal computed tomography scan) were performed after initial treatment in 122 MTC patients at the Institut Gustave Roussy between 1988 and 1998. A bone scintigraphy was also performed in patients with elevated postoperative CT levels. Postoperative imaging was abnormal in 59 patients and normal in 63 patients. These 63 patients constitute the population in this retrospective study. Pathologic diagnoses were all reviewed by a single pathologist (B Caillou, Institut Gustave Roussy). Medullary Thyroid Carcinomas were classified as either sporadic or hereditary according to the familial history and the RET protooncogene analysis. 
Total thyroidectomy was performed in all patients. A complete lymph node neck dissection (LND) was defined as a dissection of bilateral central and lateral lymph nodes; otherwise it was considered incomplete. Tumours were defined according to the tumour-node-metastasis (TNM) classification (Hermanech and Sobin, 1992, p 35) ( $\mathrm{T}$ stands for the tumour size: $\mathrm{T} 1$ : diameter $\leqslant 1 \mathrm{~cm} ; \mathrm{T} 2$ : diameter $>1 \mathrm{~cm}$ and $\leqslant 4 \mathrm{~cm} ; \mathrm{T} 3$ : diameter $>4 \mathrm{~cm}$; T4: any size but extension beyond the thyroid capsule; $\mathrm{N}$ stands for the lymph node metastases: N0 - without and N1 - with lymph node metastases; $\mathrm{M}$ stands for distant metastases: M0 - without and M1 with distant metastases). According to T, $\mathrm{N}$ and $\mathrm{M}$, four stages are individualised: stage I: T1N0M0; stage II: T2-4N0M0; stage III: T1-4N1M0; stage IV: T1-4N0-1M1). In 22 patients, more than one surgical procedure was performed within 18 months for incomplete LND and elevated postoperative CT. Follow-up started after the last surgical procedure. Eleven patients received postoperative external radiation therapy to the neck.

Between 6 weeks and 3 months after surgery, plasma CT (ELSACT, CIS-Bio International, Gif-sur-Yvette, France; normal range $<10 \mathrm{pg} \mathrm{ml}^{-1}$ ) was measured. In 27 of the 35 patients with an undetectable basal plasma CT, a pentagastrin stimulation test was performed (slow intravenous injection of $0.5 \mu \mathrm{g} \mathrm{kg}^{-1}$ pentagastrin (Peptavlon, Wyeth-Ayerst Lab; Philadelphia, PA, USA) over 3 min with CT measurements before and then 3 and 5 min thereafter). Serum carcinoembryogenic antigen (CEA) (Enzymum-test CEA, Boehringer, Mannheim, Germany; normal $<7 \mathrm{ng} \mathrm{ml}^{-1}$ ) was measured more than 2 months after surgery.

Patients were then followed up every 6 months, with a clinical examination and measurement of CT and CEA levels. An imaging work-up, consisting of a neck and abdominal ultrasonography, was performed yearly. In case of elevated CT level, a chest computed tomography scan and a bone scintigraphy were also performed yearly. Imaging-detected relapse was defined as an abnormal clinical or imaging examination.

\section{Statistics}

Follow-up ended on 1 January 2002. Three- and 5-year relapse-free survival rates were calculated using the Kaplan-Meier method (Kaplan and Meier, 1958). The Rothman method (Rothman, 1978) was used to calculate the confidence interval (CI).

Prognostic factors for imaging-detected relapse were studied by using univariate log-rank tests and multivariate Cox model analyses; proportional hazard assumptions were checked using graphical methods. The following parameters were compared: age at diagnosis, gender, hereditary status, stage of the disease, tumour extension (pT) (pT4 vs. pT1-3), node status (pN), percentage of metastatic lymph node $(>10 \%$ vs $<10 \%$ of the total number of resected lymph nodes), postoperative basal plasma CT level (detectable $v s$ undetectable), external radiation therapy to the neck and the extent of LND (complete $v s$ incomplete). As the stage of the disease and the percentage of metastatic lymph node are closely linked to $\mathrm{pT}$ and $\mathrm{pN}$, and are therefore competitive factors, multivariate analysis was performed with only three factors: $\mathrm{pT}$, $\mathrm{pN}$ and postoperative basal plasma CT level.

\section{RESULTS}

\section{Patients' characteristics}

Sixty-three consecutive patients were included in the study (35 females, 28 males; Table 1). The mean age at diagnosis was 42 years (range, 3-72 years). Medullary thyroid carcinoma was sporadic in 44 patients and hereditary in 19 patients (familial MTC (FMTC), 6; multiple endocrine neoplasia type 2A (MEN 2A), 9; multiple endocrine neoplasia type 2B (MEN 2B), 4). The mean follow-up was 6.9 years (range, $0.4-13.7$ years).

A cervical LND was performed in 61 patients and was complete in 43. Two patients underwent a thyroidectomy without LND for a benign thyroid nodule, and a micro-MTC ( 4 and $5 \mathrm{~mm}$ in diameter, respectively) was discovered at the final pathological examination. Postoperative basal CT levels were undetectable and no further surgery was performed in these two cases.

Stage I MTC (T1N0M0) was diagnosed in 10 patients, stage II (T2N0M0) in 13 patients and stage III in 40 patients ( 4 T1N1M0; 25 T2N1M0; 1 T3N1M0; 10 T4N1M0).

\section{Postoperative CT and CEA levels}

After surgery, basal plasma CT was elevated in 28 patients $(44 \%)$ (median: $131 \mathrm{pg} \mathrm{ml}^{-1}$; range: $12-3772 \mathrm{pg} \mathrm{ml}^{-1}$ ), whereas it was undetectable in the other 35 patients. A pentagastrin stimulation test was performed in 27 of these 35 patients and yielded a detectable stimulated CT level in five (median: $125 \mathrm{pg} \mathrm{ml}^{-1}$; range: $43-808 \mathrm{pg} \mathrm{ml}^{-1}$ ). Carcinoembryogenic antigen, measured in 52 patients, was moderately elevated in six (mean: $20 \mathrm{ng} \mathrm{ml}^{-1}$; range: $9-26 \mathrm{ng} \mathrm{ml}^{-1}$ ). All patients with an elevated postoperative CEA level also had an elevated postoperative basal CT level (mean CT: $918 \mathrm{pg} \mathrm{ml}^{-1}$; range: $26-2000$ ). The mean follow-up was equivalent in patients with undetectable and elevated postoperative basal CT levels.

\section{Outcome}

The 3- and 5-year relapse-free survival rates were $86 \%$ (CI, 75$93 \%)$ and $79 \%(\mathrm{CI}, 66-87 \%)$, respectively. An imaging-detected

Table I Characteristics of the 63 patients with normal postoperative imaging

\begin{tabular}{|c|c|c|c|}
\hline & All patients & $\begin{array}{l}\text { Patients without } \\
\text { relapse }(n=45 ; 71 \%)\end{array}$ & $\begin{array}{l}\text { Patients with relapse } \\
\qquad(n=18 ; 29 \%)\end{array}$ \\
\hline Mean age (y) (range) & $42(3-72)$ & $42(3-7)$ & $42(\mid 1-72)$ \\
\hline Gender: male/female & $28 / 35$ & $17 / 28$ & $11 / 7$ \\
\hline Sporadic/Hereditary MTC & $44 / 19$ & $30 / 15$ & $14 / 4$ \\
\hline (FMTC/MEN 2A/MEN 2B) & $(6 / 9 / 4)$ & $(6 / 8 / 1)$ & $(0 / 1 / 3)$ \\
\hline Mean follow-up (years) (range) & $6.9(0.4-13.7)$ & $6.6(0.4-12.6)$ & $7.7(1.8-13.7)$ \\
\hline \multicolumn{4}{|l|}{ TNM stage } \\
\hline 1 & 10 & 10 & 0 \\
\hline$\|$ & 13 & 12 & । \\
\hline III & 40 & 23 & 17 \\
\hline Postoperative CT level: undetectable/elevated & $35 / 28$ & $32 / 13$ & $3 / 15$ \\
\hline Lymph node dissection: complete/incomplete/not done & $42 / 19 / 2$ & $30 / 13 / 2$ & $12 / 6 / 0$ \\
\hline Neck radiation therapy & | | & 7 & 4 \\
\hline
\end{tabular}

Abbreviations: $\mathrm{MTC}=$ medullary thyroid carcinoma; $\mathrm{MEN}=$ multiple endocrine neoplasia; FMTC $=$ familial $M T C$. TNM=tumour - node - metastasis. 
relapse occurred in 18 patients (11 males, seven females) (29\%) (Table 2). Imaging-detected relapses were located in the neck lymph nodes in eight patients, at distant sites in eight, and in both the neck and at distant sites in two. An isolated neck imagingdetected relapse developed in previously dissected areas in six patients and in areas that had not been dissected in the other two. Isolated distant metastases were found in the liver (five patients), in the chest (one patient) and in bones (two patients). In the remaining two patients, a neck imaging-detected relapse occurred in previously dissected lymph node areas with liver metastases in one and with liver and bone metastases in the other. Fifteen had an elevated postoperative CT level and three had an undetectable postoperative CT level. At the time of imaging-detected relapse, basal CT level was below $150 \mathrm{pg} \mathrm{ml}^{-1}$ in five patients (mean: $1481 \mathrm{pg} \mathrm{ml}^{-1}$; range: $20-6290$ ) and CEA level was normal in five patients (mean: $41 \mathrm{ng} \mathrm{ml}^{-1}$; range: $0-300$ ).

The 3- and 5-year overall survival rates were 98\% (CI, $91-100 \%)$ and $97 \%$ (CI, 88-99\%), respectively. Five patients died. One patient with T2N0M0 disease presented a neck relapse after 6.1 years, underwent further surgery and died of respiratory failure during the postoperative period. The other four patients died from distant metastases after 1.8, 3.7, 6.9 and 13.7 years, respectively. They all had stage III disease (two T2N1M0, two T4N1M0). Three had an elevated postoperative basal CT level and one had an undetectable postoperative basal CT level with a pentagastrinstimulated CT level at $162 \mathrm{pg} \mathrm{ml}^{-1}$.

\section{Prognostic factors for imaging-detected relapse}

Univariate analysis showed that the following parameters were significantly predictive of imaging-detected relapse (Table 3 ): the stage of the disease $(P<0.01)$, pT $(P<0.001), \mathrm{pN}(P<0.001)$, the percentage of metastatic lymph nodes $(P<0.01)$ and the postoperative plasma CT level $(P<0.001)$. Gender, age at diagnosis and hereditary status of the disease were not statistically significant. The results were not modified when postoperative external radiotherapy and the extent of lymph node dissection were included in the analysis.

The stage of the disease, tumour extension, node status, percentage of metastatic lymph nodes and postoperative plasma CT level were highly interrelated since all pT4 patients had lymph node metastases, all had more than $10 \%$ of metastatic lymph nodes and all except one had a detectable postoperative basal CT level. The percentage of metastatic lymph nodes and the stage of the disease were therefore excluded from the multivariate analysis which was performed with only three parameters: $\mathrm{pT}, \mathrm{pN}$ and postoperative basal CT level. The independent significant prognostic parameters for imaging-detected relapse were the postoperative plasma CT level $(P<0.01)$ and the tumour extension $(P<0.05)$. $\mathrm{pN}$ was not an independent, statistically significant prognostic parameter $(P=0.1)$.

The 3- and 5-year relapse-free survival rates were 94\% (CI, $80-$ $98 \%$ ) and $90 \%$ (CI, 75-97\%), respectively, in the 35 patients with an undetectable postoperative basal CT level, and 78\% (CI, 59$90 \%)$ and $61 \%$ (CI, $41-77 \%)$, respectively, in the 28 patients with detectable postoperative basal CT level $(P<0.005)$ (Figure 1). An imaging-detected relapse occurred in three of the 35 patients $(9 \%)$ with an undetectable postoperative basal CT level and in 15 of the 28 patients $(54 \%)$ with an elevated postoperative basal CT level (Table 2). In the three patients with an undetectable postoperative CT level who relapsed, postoperative pentagastrin-stimulated CT level was undetectable in one patient and attained 43 and $162 \mathrm{pg} \mathrm{ml}^{-1}$ respectively in the other two.

The 3- and 5-year relapse-free survival rates were 92\% (CI, $81-$ $87 \%)$ and $85 \%(\mathrm{CI}, 72-93 \%)$, respectively, in the $53 \mathrm{pT} 1-3$ patients, and $57 \%$ (CI, 28-82\%) and $48 \%$ (CI, 20-74\%), respectively, in the 10 pT4 patients $(P<0.001)$. An imagingdetected relapse occurred in 11 patients with a pT1-3 tumour

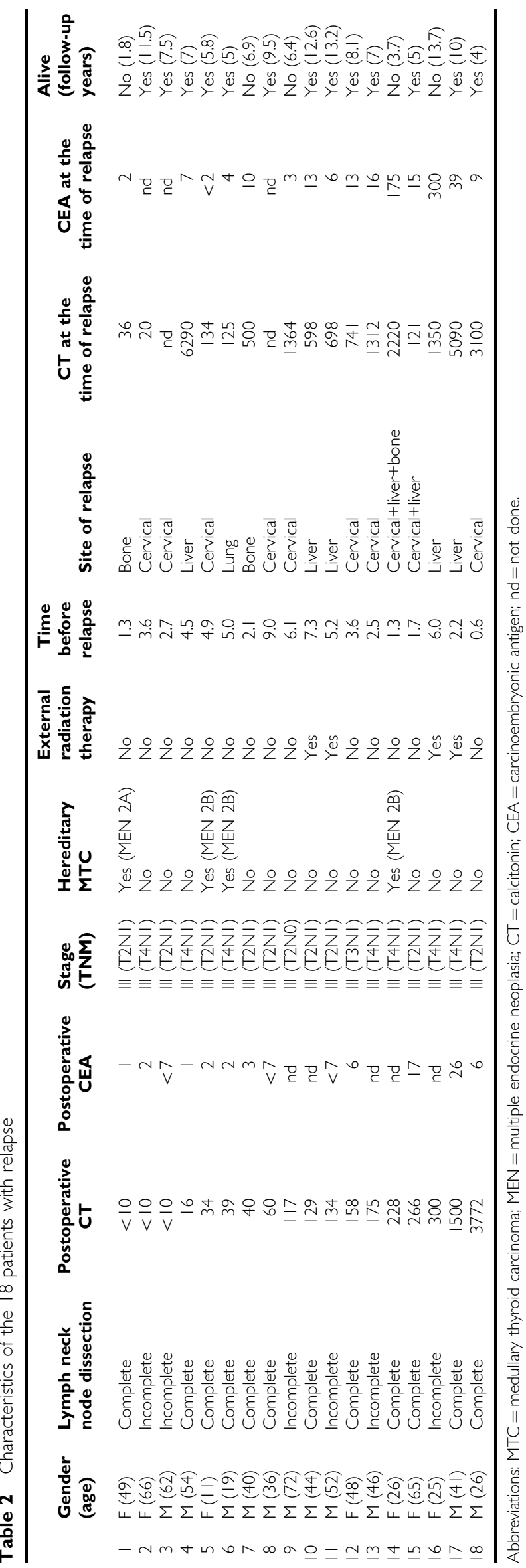

British Journal of Cancer (2003) 88(I0), 1537 - 1542 
Table 3 Prognostic factors for relapse

\begin{tabular}{|c|c|c|c|c|c|c|}
\hline & $n$ & $\begin{array}{c}\text { 3-year } \\
\text { relapse-free } \\
\text { survival (\%) }\end{array}$ & Cl 95\% & $\begin{array}{c}\text { 5-year } \\
\text { relapse-free } \\
\text { survival (\%) }\end{array}$ & Cl $95 \%$ & $P$ \\
\hline \multicolumn{7}{|l|}{ Stage } \\
\hline i & 10 & 100 & - & 100 & - & \multirow[t]{3}{*}{0.003} \\
\hline$\|$ & 13 & 100 & - & 100 & - & \\
\hline III & 40 & 78 & {$[63-89]$} & 61 & {$[44-76]$} & \\
\hline \multicolumn{7}{|c|}{ Tumour extension } \\
\hline PTI-T3 & 53 & 92 & {$[81-87]$} & 85 & {$[72-93]$} & \multirow[t]{2}{*}{0.0003} \\
\hline pT4 & 10 & 57 & {$[28-82]$} & 46 & {$[20-74]$} & \\
\hline \multicolumn{7}{|l|}{ Node } \\
\hline NO & 23 & 100 & - & 100 & {$[68-87]$} & \multirow{2}{*}{0.0006} \\
\hline $\mathrm{NI}$ & 40 & 78 & {$[63-89]$} & 65 & {$[44-80]$} & \\
\hline \multicolumn{7}{|c|}{ Postoperative CT level } \\
\hline Undetectable & 35 & 94 & {$[80-98]$} & 90 & {$[75-97]$} & \multirow[t]{2}{*}{0.0009} \\
\hline Detectable & 28 & 78 & {$[59-90]$} & 61 & {$[4 \mid-77]$} & \\
\hline \multicolumn{7}{|c|}{ Percentage of lymph node metastases } \\
\hline$<10 \%$ & 28 & 100 & - & 90 & {$[68-87]$} & \multirow[t]{2}{*}{0.004} \\
\hline$\geqslant 10 \%$ & 26 & 72 & {$[53-86]$} & 64 & {$[44-80]$} & \\
\hline \multicolumn{7}{|l|}{ Gender } \\
\hline Female & 35 & 88 & {$[72-95]$} & 81 & {$[64-9 \mid]$} & \multirow{2}{*}{0.089} \\
\hline Male & 28 & 85 & {$[67-94]$} & 76 & {$[66-88]$} & \\
\hline \multicolumn{7}{|l|}{ Age at diagnosis } \\
\hline$<45$ years & 31 & 83 & {$[66-93]$} & 79 & {$[60-90]$} & \multirow[t]{2}{*}{0.53} \\
\hline$\geqslant 45$ years & 32 & 90 & {$[74-97]$} & 79 & {$[61-90]$} & \\
\hline \multicolumn{7}{|c|}{ Hereditary disease } \\
\hline Yes & 22 & 91 & {$[7 \mid-97]$} & 85 & {$[63-95]$} & \multirow[t]{2}{*}{0.165} \\
\hline No & 41 & 84 & {$[70-93]$} & 75 & {$[59-87]$} & \\
\hline \multicolumn{7}{|c|}{ External radiation therapy } \\
\hline Yes & 11 & 91 & {$[62-98]$} & 79.5 & {$[48-94]$} & \multirow[t]{2}{*}{0.98} \\
\hline No & 52 & 86 & {$[73-93]$} & 75.6 & {$[61-86]$} & \\
\hline \multicolumn{7}{|c|}{ Lymph node dissection } \\
\hline Complete & 42 & 88 & {$[74-95]$} & 79 & {$[63-89]$} & \multirow[t]{2}{*}{0.86} \\
\hline Incomplete & 21 & 84 & {$[62-95]$} & 78 & {$[55-91]$} & \\
\hline
\end{tabular}

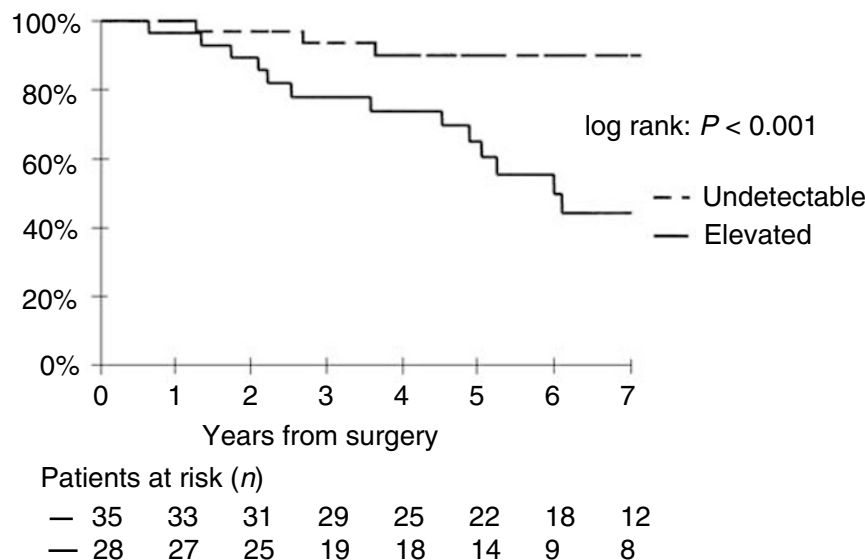

Figure I Relapse-free survival according to basal postoperative CT level.

(10pT2 and 1pT3) and in seven patients with a pT4 tumour. In patients with elevated postoperative basal CT level, the 5-year relapse-free survival rate was $84 \%(\mathrm{CI}, 62-95 \%)$ in $\mathrm{pT} 1-3$ patients and $35 \%(\mathrm{CI}, 11-70 \%)$ in pT4 patients (Figure 2). The difference is, however, not statistically significant $(P=0.2)$.

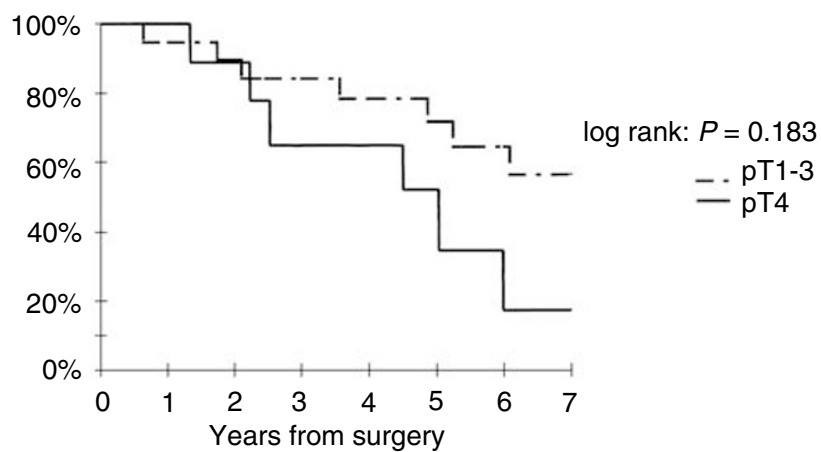

Patients at risk $(n)$

$$
\begin{array}{llllllll}
-19 & 18 & 17 & 14 & 13 & 11 & 8 & 7 \\
-9 & 9 & 8 & 5 & 5 & 3 & 1 & 1
\end{array}
$$

Figure 2 Relapse-free survival in patients with elevated basal postoperative CT level according to $\mathrm{PT}$.

The 3- and 5-year relapse-free survival rates were both $100 \%$ in the 23 pT1-3 N0 patients and $86 \%(\mathrm{CI}, 69-94 \%)$ and $72 \%(\mathrm{CI}$, $52-86 \%)$, respectively, in the $30 \mathrm{pT} 1-3 \mathrm{~N} 1$ patients $(P<0.001)$. 


\section{DISCUSSION}

Nonmetastatic MTC has a favourable prognosis. However, the 10year overall survival rate varied widely among series, from 55 up to $100 \%$ respectively (Rougier et al, 1983; Saad et al, 1984; Schroder et al, 1988; Raue et al, 1993; Dottorini et al, 1996; Scopsi et al, 1996; Bergholm et al, 1997; Modigliani et al, 1998). As therapy should be adapted to the prognosis of the disease, the identification of patients at high risk of relapse is essential. In the present study on 63 patients with normal postoperative imaging and either an undetectable postoperative basal CT level or an elevated postoperative basal CT level, the 3- and 5-year overall survival rates were 98 and 97\%, respectively. Imaging-detected relapse occurred in $29 \%$ of the patients, and the 3- and 5-year relapse-free survival rates were 86 and $79 \%$, respectively. In patients with elevated postoperative basal CT level, the 5-year relapse-free survival rate was $61 \%$, similar to that reported by van Heerden et al (1990).

The prognostic factors for survival of MTC patients include the age at diagnosis, the gender and the TNM classification (Schroder et al, 1988; Raue et al, 1993; Dottorini et al, 1996; Scopsi et al, 1996; Bergholm et al, 1997; Modigliani et al, 1998; Kebebew et al, 2000a). Data concerning MTC patients with normal postoperative imaging are few. In one study where the age was below 35 years, the presence of more than three metastatic nodes at initial surgery was found to be a significant prognostic factor for relapse at univariate analysis (van Heerden et al, 1990). In our study, at univariate analysis, stage of the disease, $\mathrm{pT}, \mathrm{pN}$, percentage of metastatic lymph nodes and postoperative basal CT level were found to be prognostic factors for imaging-detected relapse. Owing to a high link between stage, percentage of metastatic lymph nodes, $\mathrm{pT}$ and $\mathrm{pN}$, multivariate analysis was performed on $\mathrm{pT}, \mathrm{pN}$ and postoperative basal CT level. Only the postoperative basal CT level and pT were independent prognostic factors.

Calcitonin is a highly sensitive marker of persistent disease that is more sensitive than any other imaging modality (Frank-Raue et al, 1992; Abdelmoumene et al, 1994). Elevated postoperative basal CT level was described as a survival prognostic factor (Dottorini et al, 1996; Modigliani et al, 1998). In our study, it appeared prognostic for imaging-detected relapse. An imagingdetected relapse occurred in $54 \%$ of the patients with an elevated postoperative basal CT level and in $9 \%$ of the patients with an undetectable postoperative basal CT level. Our active follow-up permitted the early diagnosis of recurrences at a stage when basal CT level was below $150 \mathrm{pg} \mathrm{ml}^{-1}$ and CEA level was still in the normal range (five patients). In patients with postoperative undetectable basal CT level, a pentagastrin-stimulated test should be performed, when possible. However, even an undetectable pentagastrin-stimulated CT level does not totally exclude the risk of relapse, and this was observed in one of our patients, in accordance with another study (Modigliani et al, 1998). This underlines the need for prolonged follow-up in all MTC patients.

Tumour extension is, in our study and in others, a significant independent prognostic factor (Scopsi et al, 1996). In our study, in the group of patients with an elevated postoperative basal CT level, the risk of relapse was even higher when the tumour was pT4. In this group, we did not, however, show a significant difference in relapse-free survival, probably because of the very low number of patients.

Node status was identified as a prognostic factor in the univariate analysis in our study and in others (Schroder et al, 1988; van Heerden et al, 1990; Raue et al, 1993; Dottorini et al, 1996; Scopsi et al, 1996; Bergholm et al, 1997; Modigliani et al, 1998; Hyer et al, 2000; Kebebew et al, 2000a). In another study, with rising numbers of metastatic lymph node, gross distant metastases occurred more frequently and postoperative basal CT level was less often normalised (Machens et al, 2000). In our study, among pT13 patients, a relapse occurred in none of the pN0 patients and in $37 \%$ of the pN1 patients. Among pT4N1 patients, a relapse occurred in $70 \%$. Taken together, these data suggested that both tumour extension and nodal involvement were prognostic indicators of relapse. However, the strong interrelation between $\mathrm{pT}$ and $\mathrm{pN}$ was responsible for a competition between these two factors in the multivariate analysis.

This study allowed us to identify patients with a high risk of relapse among those with normal postoperative imaging, in whom an aggressive therapeutic approach should be considered. In retrospective studies, external radiation therapy to the neck was associated with a decreased risk of local relapse with a controversial effect on survival (Rougier et al, 1983; Samaan et al, 1988; Fersht et al, 2001). In our study, external radiation therapy was not found to be a prognostic factor, but was performed only in a few patients either with pT1-3 tumour or pT4 tumour. Nevertheless, external radiation therapy should be discussed in patients with an elevated postoperative CT level and a pT4 tumour. As the response rate to cytotoxic treatments is below $20 \%$ and as responses are partial and transient (Schlumberger et al, 1995), there is no place for adjuvant chemotherapy in MTC patients with normal imaging. It should only be given to patients with rapidly progressive metastatic disease.

\section{ACKNOWLEDGEMENTS}

We are indebted to Catherine Martin for secretarial assistance, to the nurses of the Nuclear Medicine Department for technical assistance and to Lorna Saint-Ange for editing. This work was supported in part by PHRC 1995 and C Scollo was the recipient of an Associazione Italiana Ricerca sul Cancro (AIRC) fellowship.

\section{REFERENCES}

Abdelmoumene N, Schlumberger M, Gardet P, Roche A, Travagli JP, Francese C, Parmentier C (1994) Selective venous sampling catheterisation for localisation of persisting medullary thyroid carcinoma. $\mathrm{Br} J$ Cancer 69: $1141-1144$

Bergholm U, Bergstrom R, Ekbom A (1997) Long-term follow-up of patients with medullary carcinoma of the thyroid. Cancer 79: $132-138$

Dottorini ME, Assi A, Sironi M, Sangalli G, Spreafico G, Colombo L (1996) Multivariate analysis of patients with medullary thyroid carcinoma. Prognostic significance and impact on treatment of clinical and pathologic variables. Cancer 77: 1556-1565

Fersht N, Vini L, A'Hern R, Harmer C (2001) The role of radiotherapy in the management of elevated calcitonin after surgery for medullary thyroid cancer. Thyroid 11: 1161-1168
Frank-Raue K, Raue F, Buhr HJ, Baldauf G, Lorenz D, Ziegler R (1992) Localization of occult persisting medullary thyroid carcinoma before microsurgical reoperation: high sensitivity of selective venous catheterization. Thyroid 2: $113-117$

Hermanek P, Sobin L (1992) Thyroid gland (ICD-OC73). In TNM Classification of Malignant Tumors. 4th edn, 2nd revision, Hermanek P, Sobin L (eds) pp. 35-37. Berlin: Springer-Verlag

Hyer SL, Vini L, A'Hern R, Harmer C (2000) Medullary thyroid cancer: multivariate analysis of prognostic factors influencing survival. Eur J Surg Oncol 26: 686-690

Kaplan EL, Meier P (1958) Non parametric estimation from incomplete observations. J Am Statist Assoc 53: 457-481

Kebebew E, Ituarte PH, Siperstein AE, Duh QY, Clark OH (2000a) Medullary thyroid carcinoma: clinical characteristics, treatment, prog- 
nostic factors, and a comparison of staging systems. Cancer 88: $1139-1148$

Kebebew E, Kikuchi S, Duh QY, Clark OH (2000b) Long-term results of reoperation and localizing studies in patients with persistent or recurrent medullary thyroid cancer. Arch Surg 135: 895-901

Machens A, Gimm O, Ukkat J, Hinze R, Schneyer U, Dralle H (2000) Improved prediction of calcitonin normalization in medullary thyroid carcinoma patients by quantitative lymph node analysis. Cancer 88: $1909-1915$

Modigliani E, Cohen R, Campos JM, Conte-Devolx B, Maes B, Boneu A, Schlumberger M, Bigorgne JC, Dumontier P, Leclerc L, Corcuff B, Guilhem I (1998) Prognostic factors for survival and for biochemical cure in medullary thyroid carcinoma: results in 899 patients. The GETC Study Group. Groupe d'etude des tumeurs a calcitonine. Clin Endocrinol (Oxf) 48: 265-273

Moley JF, Debenedetti MK, Dilley WG, Tisell LE, Wells SA (1998) Surgical management of patients with persistent or recurrent medullary thyroid cancer. J Intern Med 243: $521-526$

Raue F, Kotzerke J, Reinwein D, Schroder S, Roher HD, Deckart H, Hofer R, Ritter M, Seif F, Buhr H, Beyer J, Schober O, Becker W, Neumann H, Calvi J, Winter J, Vogt H, the German Medullary Thyroid Carcinoma Study Group (1993) Prognostic factors in medullary thyroid carcinoma: evaluation of 741 patients from the German Medullary Thyroid Carcinoma Register. Clin Invest 71: 7-12

Rothman KJ (1978) Estimation of confidence limits for the cumulative probability of survival in life table analysis. J Chronic Dis 31: 557-560
Rougier P, Parmentier C, Laplanche A, Lefevre M, Travagli JP, Caillou B, Schlumberger M, Lacour J, Tubiana M (1983) Medullary thyroid carcinoma: prognostic factors and treatment. Int J Radiat Oncol Biol Phys 9: $161-169$

Saad MF, Fritsche Jr HA, Samaan NA (1984) Diagnostic and prognostic values of carcinoembryonic antigen in medullary carcinoma of the thyroid. J Clin Endocrinol Metab 58: 889-894

Samaan NA, Schultz PN, Hickey RC (1988) Medullary thyroid carcinoma: prognosis of familial versus sporadic disease and the role of radiotherapy. J Clin Endocrinol Metab 67: 801-805

Schlumberger M, Abdelmoumene N, Delisle MJ, Couette JE, Parmentier C (1995) Treatment of advanced medullary thyroid cancer with an alternative combination of 5 FU-streptozotocin and 5 FU-dacarbazine. Br. J. Cancer 71: $363-365$

Schroder S, Bocker W, Baisch H, Burk CG, Arps H, Meiners I, Kastendieck H, Heitz PU, Kloppel G (1988) Prognostic factors in medullary thyroid carcinomas. Survival in relation to age, sex, stage, histology, immunocytochemistry, and DNA content. Cancer 61: 806-816

Scopsi L, Sampietro G, Boracchi P, Del Bo R, Gullo M, Placucci M, Pilotti S (1996) Multivariate analysis of prognostic factors in sporadic medullary carcinoma of the thyroid. A retrospective study of 109 consecutive patients. Cancer 78: $2173-2183$

van Heerden JA, Grant CS, Gharib H, Hay ID, Ilstrup DM (1990) Long-term course of patients with persistent hypercalcitoninemia after apparent curative primary surgery for medullary thyroid carcinoma. Ann Surg 212: $395-400$, discussion 400-1. 